\title{
The 10-year COPD Programme in Finland: effects on quality of diagnosis, smoking, prevalence, hospital admissions and mortality
}

\author{
*Vuokko L Kinnulaa, Tuula Vasankarib, Eva Kontulac, Anssi Sovijarvid, \\ Olli Saynajakangas ${ }^{e}$, Anne Pietinalho ${ }^{f}$
}

a Department of Medicine, Division of Pulmonary Medicine, University of Helsinki, Helsinki, Finland

${ }^{\mathrm{b}}$ Department of Respiratory Medicine, Turku University Hospital, Preitila, Finland

' Janakkala Health Care Center, Janakkala, Finland

${ }^{d}$ Department of Clinical Physiology, University of Helsinki and Helsinki University Hospital, Helsinki, Finland

e Department of Pulmonary Medicine, Lapland Central Hospital, Rovaniemi, Finland

Finnish Lung Health Association (FILHA) and Department of Pulmonary Medicine, Helsinki University Hospital/Peijas Hospital, Vantaa, Finland

Originally submitted 16th September 2010; resubmitted 26th November 2010; revised 29th December 2010; accepted 4th January 2011;

online 23rd March 2011

\begin{abstract}
Background: The Finnish National Programme for Chronic Bronchitis and Chronic Obstructive Pulmonary Disease (COPD) 1998-2007 was set up to reduce the prevalence of COPD, improve COPD diagnosis and care, reduce the number of moderate to severe cases of the disease, and reduce hospitalisations and treatment costs due to COPD. Over 900 events for 25,000 participating healthcare workers were arranged. The major strengths of this programme included multidisciplinary strategies and web-based guidelines in nearly all primary health care centres around the country.

Methods: Data from national registries, epidemiological studies and questionnaires were used to measure whether the goals had been reached.

Results: The prevalence of COPD remained unchanged. Smoking decreased in males from 30\% to $26 \%(p<0.001)$ and in females from $20 \%$ to $17 \%$ ( $p<0.001)$. Significant improvements in the quality of spirometry were obtained. Hospitalisation decreased by $39.7 \%(p<0.001)$. COPD costs were $88 \%$ lower than had been anticipated from earlier investigations. No increase in COPD mortality was observed.

Conclusions: In combination with other efforts, the Finnish 10-year COPD Programme had significant positive consequences: no further increases in COPD prevalence, reduced smoking prevalence, improved quality of diagnosis, and reduction in COPD-related hospitalisations.

(C) 2011 Primary Care Respiratory Society UK. All rights reserved.

V Kinnula et al. Prim Care Respir J 2011; 20(2): 178-183

doi: 10.4104/pcrj.2011.00024
\end{abstract}

Keywords COPD, chronic bronchitis, diagnosis, smoking cessation, screening, prevalence, management, hospital admissions, mortality, Finland

See linked editorial by Calverley on pg 109

\section{Introduction}

In 1994, the Finnish Ministry of Social Affairs and Health inaugurated the Finnish 10-year Asthma Programme. 1,2 Since then, the importance of chronic obstructive pulmonary disease (COPD) has been recognised worldwide. ${ }^{3}$ In Finland, the Ministry of Social Affairs and Health provided funds for the setting-up of a COPD prevention and treatment Programme. The National Programme of Chronic Bronchitis and Chronic Obstructive Pulmonary Disease 1998-2007 was designed by FILHA (The Finnish Lung Health Association (www.filha.fi), a nongovernmental organisation (NGO), between 1996 and 1997, together with the Ministry of Social Affairs and Health, the

\footnotetext{
* Corresponding author: Professor Vuokko Kinnula, Department of Medicine, Division of Pulmonary Medicine, University of Helsinki, PO.Box 22, Haartmaninkatu 4, Helsinki, Fl-00014, Finland. Tel: +358 947172255 Fax: +358 947176107 E-mail: vuokko.kinnula@helsinki.fi
} 
Pulmonary Association HELI (NGO), and an expert panel. It was subsequently launched by the Ministry of Social Affairs and Health in 1998. ${ }^{4,5}$ The results of the first five years have been published. ${ }^{6}$

The major aims of this 10-year COPD Programme in Finland, a country with a population of 5 million, included:

1) a reduction in COPD prevalence

2) improvement in COPD diagnosis, especially in primary care

3) a reduction in the number of moderate to severe cases of the disease

4) reduction in the number of COPD-related hospitalisations, and

5) reduction in treatment costs due to COPD.

The implementation of the Programme started with all central hospitals ( $n=21)$ and occupational health districts $(n=6)$, and over the next few years it spread to all 271 primary health care centres (PHCCs) in the country. In addition, the first Finnish evidence-based guidelines for COPD were published by the Finnish Medical Society "Duodecim" in 1999; these were updated in 2004 and 2010 (www.Duodecim.fi) and were included in the Programme implementation.

According to the Finnish National Asthma Programme, at least one asthma nurse and asthma doctor was nominated in every PHCC to be responsible for the care of asthma patients. The same nurses and doctors were now nominated to be responsible for the COPD patients in their PHCC as well. At the end of the Programme there were 280 local asthma/COPD physicians and 690 asthma/COPD nurses in primary care.

Pharmacies expanded into the field of COPD and smoking cessation. The Pulmonary Association HELI, a patient organisation, was responsible for direct patient counselling, and a free-of-charge "quit line" for smoking (called Stumppi) handled over 3,000 contacts/year between 2003 and 2007. An internet-based page for smokers became available from 2005 (www.stumppi.fi). Approximately 330,000 individuals every year contacted the advice line seeking help to quit smoking. The Network of Smoke Free Hospitals was originally set up in Finland in 1985 in a few hospital districts, and at the end of the programme all but two hospital districts were smoke-free. A new impetus to the network came in 2002, when the Finnish Medical Society Duodecim published evidence-based recommendations for smoking cessation (www.Duodecim.fi). ${ }^{8}$ Web-based brief guidelines were introduced to nearly all PHCCs and hospitals by Duodecim and by the current COPD Programme. The number of visits to the Duodecim website for advice on COPD was 13,157, for advice on asthma 25,928, and for advice on anti-smoking strategies 17,875.

Especially with regard to COPD, long follow-up is necessary to evaluate the effect of these sorts of changes on prevalence, diagnosis and management, particularly in primary care. This paper presents the overall results of the 10-year Finnish National Programme for COPD.

\section{Methods}

\section{Epidemiology}

The prevalence of COPD was evaluated from recent Finnish epidemiological studies on COPD. ${ }^{9,10}$ The first study, published in 2005, ${ }^{9}$ estimated the prevalence of COPD in 1995-1996 based on GOLD criteria and Finnish reference values, and the second study evaluated COPD prevalence between the years 1978-1980 and 2000-2001.10 The follow-up periods of these studies did not cover the entire span of the 10-year Programme (which ended in 2007), but they did assess prevalence over a relatively long, 20-year period.

\section{Evaluation of the quality of spirometry}

The quality of spirometry both in primary and secondary care was evaluated by FILHA in 1999 and 2007.11,12 The surveys were conducted by sending the same interview in 1999 and 2007 to all PHCCs performing spirometries. The Finnish guidelines for performing and evaluating spirometry have been published and updated since 1995 by the Finnish Society of Clinical Physiology and the Finnish Respiratory Society. ${ }^{13}$

\section{Smoking}

Tobacco statistics came mainly from Statistics Finland and from the National Institute of Health and Welfare (THL). ${ }^{14,15} \mathrm{THL}$ sends an annual questionnaire to 5,000 adults (between the ages of 15 and 64) asking several questions such as smoking status, physical activity, alcohol consumption and diet. Smoking habits for 1997 and 2007 were evaluated based on this annual questionnaire.

\section{Changes in hospitalisation days}

The numbers of hospitalisation days were obtained from the national registry of hospital care (HILMO registry, THL) for the years 1997-2007.

\section{Costs}

In the beginning of the Programme, the total annual costs of COPD were estimated to be approximately 0.8 billion euros. ${ }^{4}$ When the Programme was finished the cost was estimated from various Finnish national health registries including the Social Insurance Institution of Finland, the National Research and Development Centre for Welfare and Health (STAKES), and the National Agency of Medicines (NAM). The prevalence of COPD was based on cost-of-illness estimation. The direct costs consisted of the expenses based on the use of inhaled anticholinergics, rehabilitation and devices obtained from the Social Insurance Institution of Finland (KELA), the main organisation for handling retirements and rehabilitation courses. The productivity losses due to COPD were regarded as indirect costs. $^{16}$

\section{Mortality}

Mortality was evaluated from the national death statistics for 1997 and 2007.

\section{Statistics}

The Chi-squared test was used to test the differences in the use 
of recommended reference values and calibration between the years 1999 and 2007. The differences are given as risk ratios (RR) with 95\% confidence intervals. Cochran-Armitage Trend Test was used to analyse the trends of smoking habits. Pearsons Bivariate Correlation test in SPSS statistical program was used to evaluate the significance of change in trends of hospital days.

\section{Results}

\section{Trends in COPD prevalence}

In the whole adult population the prevalence of COPD was $4.7 \%$ in males and $2.2 \%$ in females in 1978-1980 and $4.3 \%$ and $3.1 \%$, respectively in 2000-2001, data that has been published recently. ${ }^{10}$ Even though the period does not cover the entire duration of this Programme, it shows that the prevalence of COPD has not increased significantly over two decades.

\section{Improvements in the quality of spirometry}

The quality of spirometry significantly improved from 1999 to 2007. Use of the recommended Finnish reference values increased significantly, from $85 \%$ to $92 \%$, with a risk ratio of 1.08 (95\% Cl 1.04 to $1.13, p<0.001)$. The numbers of those who were calibrating their equipment every day or before every examination increased significantly, from $39 \%$ to $83 \%$, with a risk ratio of $2.12(1.91$ to $2.35, p<0.001))^{11,12}$ The number of workplaces which never calibrated their spirometry machines decreased from $9 \%$ to $2 \%$, with a risk ratio of $0.38(0.24$ to $0.59, \mathrm{p}<0.001$ ) (see Figure 1). In 1999, 203 workplaces and in 2007, 227 centres answered all questions in the quality index (see Table 1). The mean quality index was 66 (max 100, see Table 1) in both evaluations..$^{11,12}$

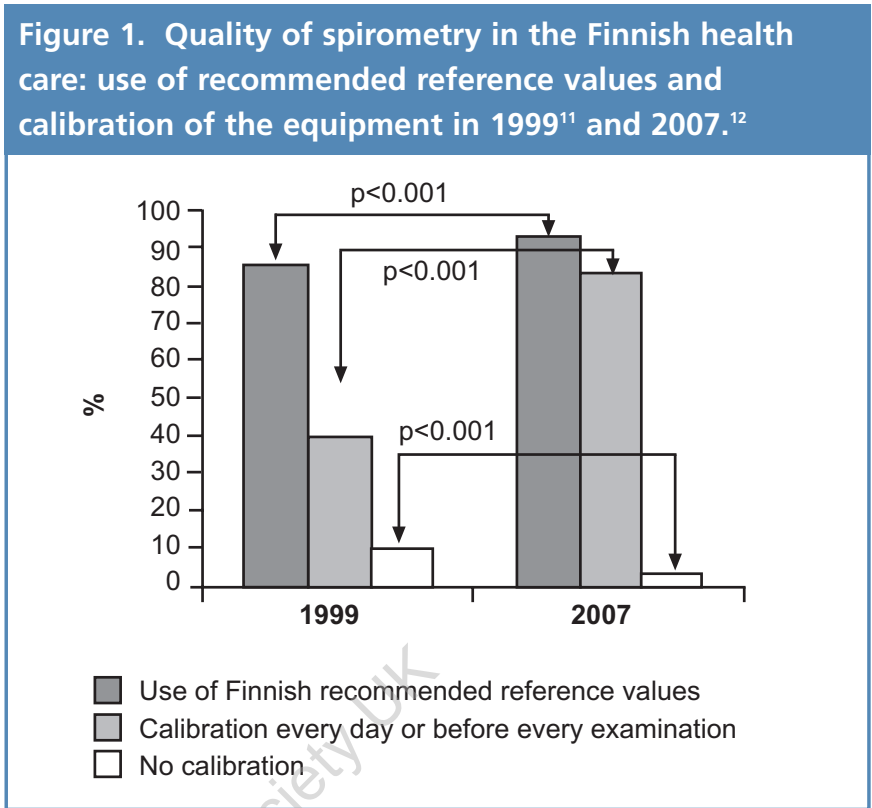

\section{Efficacy of smoking cessation measures}

Smoking prevalence in Finland showed a modest decline between 1997 and 2007, from $30 \%$ to $26 \%(p<0.001)$ in males, and from $20 \%$ to $17 \%(p<0.001)$ in female adults (see Figure 2) (www.thl.fi). ${ }^{14,15}$

\section{Decreased hospitalisations due to COPD}

The number of hospitalisations days due to COPD reduced by $39.7 \%(p<0.001)$ between 1997 and 2007. This reduction was greatest $(52.9 \%)(p<0.001)$ for men aged 65 years or over (see Figure 3). In addition, the number of hospital

\section{Table 1. Quality index of spirometry, list of quality criteria and maximum scores for them. ${ }^{11, \text { revised }}$}

\begin{tabular}{|c|c|}
\hline Question & Maximum score (points) \\
\hline 1. Time allowed for the examination & 6 \\
\hline 2. Calibration frequency & 6 \\
\hline 3. Are there written instructions on calibration? & 2 \\
\hline 4. Use of nasal closure & 4 \\
\hline 5. Asking about the patient's medication and drawing a conclusion on the basis of the answer & 10 \\
\hline 6. Qualification criteria for one expiration & 8 \\
\hline 7. Curve repeatability criteria & 12 \\
\hline 8. Reference value practice & 8 \\
\hline 9. Observing the Finnish recommendations of spirometry & 4 \\
\hline 10. Printing of sub curves & 6 \\
\hline 11. A graphical outcome curve is given & 4 \\
\hline 12. Printed parameters & 15 \\
\hline 13. Giving of spirometry statement & 5 \\
\hline 15. Attendance at operator training or spirometry courses in proportion to the number of employees & 10 \\
\hline Total & 100 \\
\hline
\end{tabular}




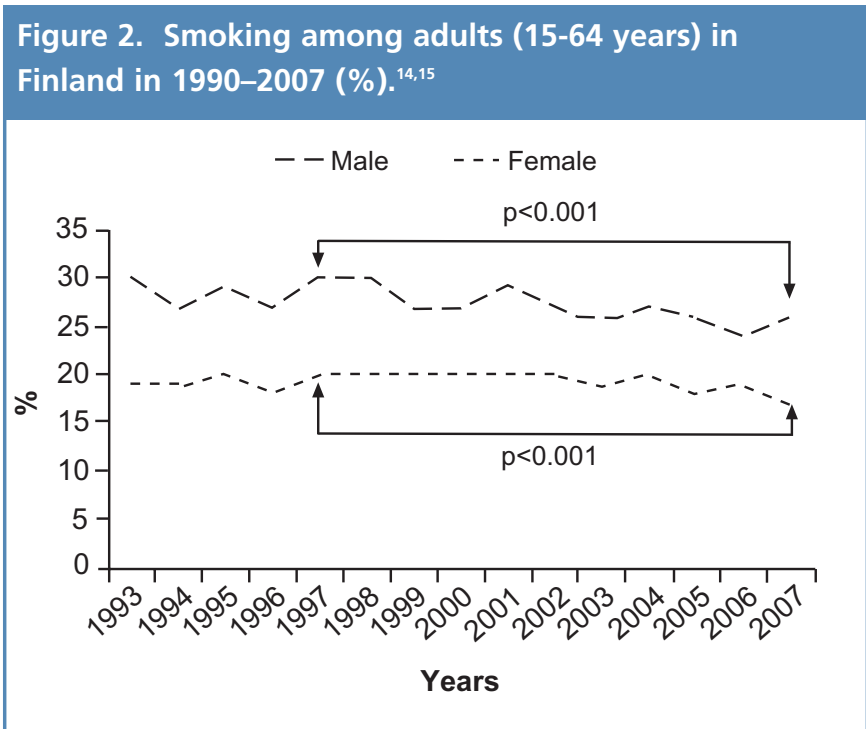

Figure 3. COPD-induced hospital treatment days in the age group 35-64 years for men and for women and in the age group 65 years or older for men and for women in relation to the population in 1997-2007.

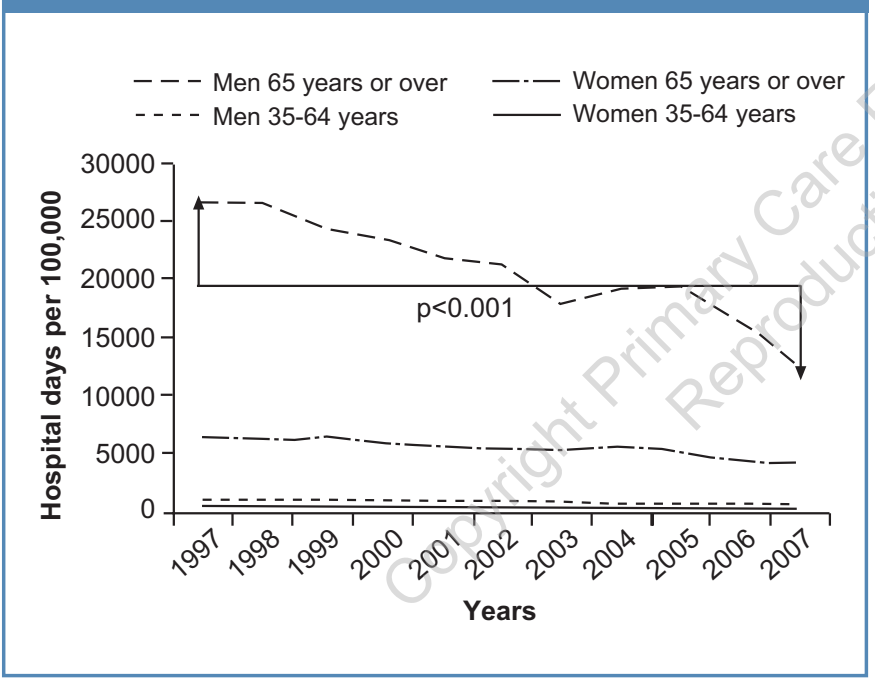

periods fell by $37.6 \%(p<0.001)$.

\section{Costs due to COPD}

At the end of the Programme, the total annual societal costs of COPD were calculated to be $€ 194$ million, of which more than half were direct costs. The majority (34\%) of direct costs were related to hospital inpatient care, early retirements being a key component $(25 \%)$ of indirect costs. ${ }^{16}$

\section{Unchanged mortality}

There were 1055 deaths due to COPD in 1997. The majority of them, 795 cases (75\%), occurred in men. In 2007 there were 1,094 deaths, of which 806 (74\%) were in males (www.stat.fi). There is no statistically significant difference in the number of deaths due to COPD between the years 1997 and 2007.

\section{Discussion}

Ten to 20 years ago, COPD was an almost totally unknown disease in primary care in Finland. After the 10-year COPD Programme had been launched in 1998, it made a rapid and extensive contribution to COPD awareness. In addition to this 10-year Programme, there were several other Finnish initiatives directed towards smoking cessation and COPD recognition during the same period. These include the COPD and smoking cessation guidelines by the Finnish Medical Society Duodecim (updated regularly), legislation banning smoking in workplaces, hospitals and public places (in 1995) and restaurants (in 2003 and 2006), and national guidelines for spirometry (updated regularly since 1995). ${ }^{13}$ There have been many advances made during the COPD Programme, both as a result of the programme itself and also independent of it.

Since there are only a few available epidemiological studies on the prevalence of COPD in Finland, $, 17,18$ and given that our follow-up period was relatively short, no reduction in COPD prevalence could be detected between 1997 and 2007. However, according to a recent study, the prevalence of COPD has not changed significantly in Finland between 1980 and 2001,10 reflecting the possible long-term change in smoking habits in both genders; in the 1950 s, $75 \%$ of men and $10 \%$ of women smoked, but in the 1990 s only $30 \%$ of men and $20 \%$ of women smoked (www.thl.fi).

One characteristic feature and strength in the Finnish healthcare system - especially in the field of chronic airway diseases - is the multidisciplinary strategy, which continued in the COPD Programme. These individuals have taken clear responsibility for the diagnostic process as well as spirometry and its quality control, and importantly, have participated in smoking cessation counselling and education. It is, however, too early to know how the long term follow-up and treatment of COPD really succeeded.

An obvious reduction in hospital admission days was seen during this Programme (from 34,600 to $18,000, p<0.001$ ). This is surprising, since smoking tends to impact on COPD development after many years., ${ }^{41}$ The structure of the healthcare system in Finland has changed over the past few decades. In addition to the guidelines listed above, the Finnish Medical Society Duodecim also launched evidence-based treatment guidelines for respiratory failure which included a section on non-invasive ventilation (www.duodecim.fi) - and this instruction is now widely adopted in all emergency units throughout the country. The development of pharmacological treatment for COPD has evidently contributed to the decreased numbers of disease exacerbations. ${ }^{19-21}$ Overall, hospital stays due to COPD are declining in Finland for many reasons including the presence of a national network of experienced asthma/COPD doctors and nurses and efficacious treatment for severe exacerbations including the widespread use of non-invasive 
ventilation in the most severe COPD cases.

It has been claimed that mortality due to COPD will increase so that it becomes the third most common killer on a global scale, ${ }^{22}$ mainly (though not totally) due to smoking., ${ }^{4,23,24}$ Finland represents a country with low environmental tobacco exposure and a relatively low smoking prevalence compared to many other countries (www.who.TobaccoAtlas ${ }^{25}$ ). Other factors such as high living standards and education, and high quality patient care, may have some effects as well. However, it can be assumed that real mortality due to COPD may be somewhat higher due to other co-morbidities, lack of autopsy evidence, and persisting inadequate awareness of COPD. However, Finnish mortality statistics show no trend towards this anticipated increase in COPD mortality.

COPD costs were estimated to be approximately $€ 0.8$ billion at the onset of the Programme. ${ }^{4,5}$ The costs were found to be much lower than expected according to previous reports. ${ }^{16} \mathrm{~A}$ statistical difference could not be calculated between the initial cost estimation and the study conducted in $2006^{16}$ because of obvious differences in methodology between the evaluations. Based on these evaluations, the overall cost of COPD was not increasing, and it was much less than the estimate ( $€ 0.8$ billion) in the original COPD Programme 10 years previously.

The cost of screening is difficult to estimate. The 10-year Programme did not evaluate the costs of screening separately, but it raised significant interest in the question of whether or not to screen for COPD. The programme was not opposed to screening, as per the Finnish Medical Society Duodecim guidelines. Given that the usefulness of screening has not been clearly proven, it is still not widely recommended, ${ }^{26}$ based on the fact that no medication so far has been shown to have any significant influence on COPD mortality. Moreover, screening may not necessarily lead to smoking cessation and it may simply cause further investigations and cost. With this proviso, screening was recommended in certain situations such as in the health care units of occupational health centres where each employee has to be examined according to legislation. Another reason to include the screening option is the fact that detecting airway obstruction can be straightforward, quick, ${ }^{27}$ and not dangerous at all; on these occasions all smokers can be encouraged to quit and this may have real significance. ${ }^{28,29}$ It is also important to detect symptomatic COPD, since symptoms are likely to progress. Screening can detect moderate to severe COPD cases and in these cases there are treatments which can prevent disease exacerbations. Medical treatment of COPD has significantly improved during recent years and new drugs are under intensive development.

\section{Conclusions}

This 10-year Programme concentrated on multidisciplinary strategies, efficient and effective training, and web-based brief guidelines for use in primary care. The final results were achieved following the many initiatives listed in this publication. The 10-year follow-up period was not long enough to detect any significant decline in the prevalence of COPD, though no significant increase in COPD prevalence was found between 1980 and 2000. The number of hospitalisation days and treatment costs decreased unexpectedly. The COPD costs were lower than had been previously evaluated. Overall, awareness of COPD and the risks related to smoking have increased in Finland, and negative attitudes towards smoking in adolescents are becoming more prevalent; this in turn suggests that the positive trend observed in the survey will continue in the future.

\section{Conflicts of interest and financial declaration}

None of the authors have any conflict of interest, financial involvement or stock ownership with any aspect discussed in the manuscript. This paper has not been funded by the tobacco industry. No writing assistance has been utilised in the preparation of this manuscript.

\section{Acknowledgements}

The Ministry of Social Affairs and Health, Finland's Slot Machine Association and Finnish Lung Health Association (Filha) have supported the implementation of the COPD programme and Filha has also supported this final report of the programme. We thank Professor Kaj Koskela for his contribution to the programme and Professor Timo Klaukka for his aid in preparing the 10-year report of the programme. The COPD studies and writing process of VLK have been partly supported by the Finnish Antituberculosis Association Foundation and funded by a governmental subsidy for health science research (EVO) of Helsinki University Central Hospital.

\section{Authors' contributions}

All authors have participated in the writing process, particularly concerning their own evaluations. Specifically, AP was the main person implementing the Programme (1997-2007), and participated in the writing of the manuscript. TV was the main investigator for the newest epidemiologic study during the last 20 years. AS participated in the evaluation of spirometry in primary and secondary care. EK was the second person (in addition to AP) in implementing the Programme and working with the data evaluation. OS made the analyses to assess COPD hospitalizations. VLK evaluated the data and was the main author in the writing of, and finalisation of, the manuscript.

\section{References}

1. Haahtela T, Laitinen LA. Asthma programme in Finland 1994-2004. Report of a Working Group. Clin Exp Allergy 1996;26(Suppl 1):i-24.

2. Haahtela T, Tuomisto LE, Pietinalho $A$, et al. A 10 year asthma programme in Finland: major change for the better. Thorax 2006;61(8):663-70. http://dx.doi.org/10.1136/thx.2005.055699

3. Mannino DM, Buist AS. Global burden of COPD: risk factors, prevalence, and future trends. Lancet 2007;370(9589):765-73. http://dx.doi.org/ 10.1016/S0140-6736(07)61380-4

4. Laitinen LA, Koskela K. Chronic bronchitis and chronic obstructive pulmonary disease: Finnish National Guidelines for Prevention and Treatment 1998-2007. Respir Med 1999;93(5):297-332. http://dx.doi.org/10.1016/S09546111(99)90313-X

5. National prevention and treatment program 1998-2007. Chronic bronchitis and COPD. Publication of Social Affairs and Health 1998; 4:(in Finnish).

6. Pietinalho A, Kinnula VL, Sovijärvi $A R$, et al. Chronic bronchitis and chronic obstructive pulmonary disease. The Finnish Action Programme, interim report. Respir Med 2007;101(7):1419-25. http://dx.doi.org/10.1016/j.rmed.2007.01.022

7. COPD. Evidence based guidelines. Duodecim 1999; http://www.kaypahoito.fi (in Finnish). 
8. Working Group appointed by the Finnish Association for General Practice. Smoking, nicotine dependency and smoking cessation. Evidence Based Medicine Guideline. Duodecim 2002; http://www.kaypahoito.fi (in English).

9. Kotaniemi J., Sovijärvi A, Lundback B. Chronic obstructive pulmonary disease in Finland: prevalence and risk factors. COPD 2005; 2(3):331-9. http://dx.doi.org/10.1080/15412550500218122

10. Vasankari TM, Impivaara O, Heliovaara M, et al. No increase in the prevalence of COPD in two decades. Eur Respir J 2010;36(4):766-73. http://dx.doi.org/10.1183/09031936.00178109

11. Pietinalho A, Piirilä P, Poussa T, Lindholm T, Siukola A, Sovijärvi A. The quality of spirometry in Finland is already good - result from a national questionnaire study. Suomen Lääkärilehti 2010;65:3505-12 (in Finnish).

12. Piirilä $P$, Pietinalho $A$, Loponen $M$, et al. The quality of spirometric examinations in Finland: results from a national questionnaire survey. Clin Physiol Funct Imaging 2002;22(3):233-9. http://dx. doi.org/10.1046/j.1475-097X.2002.00424.x

13. Sovijärvi A, Kainu A, Malmberg P, Pekkanen L, Piirilä P. Performance and interpretation of spirometry and PEF measurements. Moodi 2006;10:3-19 (in Finnish).

14. Helakorpi S, Uutela A, Prättälä R, Berg A-M, Puska P. Health behaviour among Finnish adult population, Spring 1997. Publications of the National Public Health Institute B10/1997 1997.

15. Helakorpi S, Prättälä R, Uutela A. Health behaviour and health among the Finnish Adult Population, Spring 2007. Publications of the National Public Health Institute B6/2008 2008.

16. Tynkkynen LK, Klaukka T, Pietinalho A, Rissanen P. The costs of COPD in Finland are lower than estimated. Suomen Lääkärilehti 2009;64:2095-9 (in Finnish).

17. Huhti E. Prevalence of respiratory symptoms, chronic bronchitis and pulmonary emphysema in a Finnish rural population. Field survey of age group 40-64 in the Harjavalta area. Acta Tuberc Pneumol Scand Suppl 1965; Suppl-111.

18. Pallasaho $P$, Lundbäck $B$, Meren $M$, et al. Prevalence and risk factors for asthma and chronic bronchitis in the capitals Helsinki, Stockholm, and Tallinn. Respir Med 2002;96(10):759-69. http://dx.doi.org/10.1053/rmed.2002.1308
19. Tashkin DP, Celli B, Senn S, et al. A 4-year trial of tiotropium in chronic obstructive pulmonary disease. N Engl J Med 2008;359(15):1543-54. http://dx.doi.org/10.1056/NEJMoa0805800

20. Anzueto A, Miravitlles M. Efficacy of tiotropium in the prevention of exacerbations of COPD. Ther Adv Respir Dis 2009;3(3):103-11. http://dx.doi.org/10.1177/1753465809338854

21. Welte $T$, Miravitlles $M$, Hernandez $P$, et al. Efficacy and tolerability of budesonide/formoterol added to tiotropium in patients with chronic obstructive pulmonary disease. Am J Respir Crit Care Med 2009;180(8):741-50. http://dx.doi.org/10.1164/rccm.200904-04920C

22. Murray CJ, Lopez AD. Alternative projections of mortality and disability by cause 1990-2020: Global Burden of Disease Study. Lancet 1997; 349(9064):1498-504. http://dx.doi.org/10.1016/\$0140-6736(96)07492-2

23. Rabe KF, Beghe B, Luppi F, Fabbri LM. Update in chronic obstructive pulmonary disease 2006. Am J Respir Crit Care Med 2007;175(12):1222-32. http://dx.doi.org/10.1164/rccm.200704-586UP

24. Salvi SS, Barnes PJ. Chronic obstructive pulmonary disease in non-smokers. Lancet 2009;374(9691):733-43. http://dx.doi.org/10.1016/\$0140-6736(09)61303-9

25. The Tobacco Atlas 2009. www tobaccoatlas.org

26. Petty TL, Mannino DM. Will recommendations against spirometry make chronic obstructive pulmonary disease harder to treat? Ann Intern Med 2008; 149(7):512-3.

27. Rytila $P$, Helin $T$, Kinnula $V$. The use of microspirometry in detecting lowered FEV1 values in current or former cigarette smokers. Prim Care Respir J 2008; 17(4):232-7. http://dx.doi.org/10.3132/pcrj.2008.00058

28. Law $M$, Tang $\mu$. An analysis of the effectiveness of interventions intended to help people stop smoking. Arch Intern Med 1995;155(18):1933-41.

29. Toljamo T, Kaukonen M, Nieminen P, Kinnula VL. Early detection of COPD combined with individualized counselling for smoking cessation: a two-year prospective study. Scand J Prim Health Care 2010;28(1):41-6. http://dx.doi.org/10.3109/02813431003630105 